\title{
The Biodegradation of Dispersed Oil Does Not Induce Toxicity at Environmentally-Relevant Concentrations
}

\author{
Roger C. Prince*, Bryan M. Hedgpeth, Aaron D. Redman, Josh D. Butler \\ ExxonMobil Biomedical Sciences, Inc., Annandale, NJ, USA \\ Email: ${ }^{\star}$ rogercprince@gmail.com
}

How to cite this paper: Prince, R.C., Hedgpeth, B.M., Redman, A.D. and Butler, J.D. (2019) The Biodegradation of Dispersed Oil Does Not Induce Toxicity at Environmentally-Relevant Concentrations. Open Journal of Marine Science, 9, 113-120. https://doi.org/10.4236/ojms.2019.93009

Received: June 13, 2019

Accepted: July 14, 2019

Published: July 17, 2019

Copyright $\odot 2019$ by author(s) and Scientific Research Publishing Inc. This work is licensed under the Creative Commons Attribution International License (CC BY 4.0).

http://creativecommons.org/licenses/by/4.0/

\begin{abstract}
Applying dispersants to spilled crude oil results in an oil in water dispersion of microscopic oil droplets that soon dilutes to levels below $1 \mathrm{ppm}$ oil. These levels are substantially below those known to induce acute toxicity in 96-hour tests. We show here that oil hydrocarbons are biodegraded very rapidly in such situations (50\% loss in 4 days in this experiment), and that no increase in acute toxicity to mysids (Americamysis bahia) is seen during this biodegradation, or over the following 20 days as the oil is further degraded (78\% loss of detectable hydrocarbons in this experiment).
\end{abstract}

\section{Keywords}

Oil Spills, Dispersants, Biodegradation, Acute Toxicity, Hopane, Americamysis bahia

\section{Introduction}

Dispersants are important tools in oil spill response because they facilitate oil dispersion, thereby protecting birds and other animals. They also dramatically stimulate biodegradation, thereby minimizing the residency of spilled oil in the environment [1] [2]. Dispersed crude oil is measurably toxic at the concentrations found immediately after dispersion [3] [4] LC50 values, 48 - 96 hour exposure, of $2-10 \mathrm{ppm}$ [4], but these levels do not persist in the sea because within hours the dispersed plume dilutes to the sub ppm level [5] [6]. It is notable that although most samples collected following the Deepwater Horizon tragedy were collected in locations expected to be contaminated by oil, the vast majority (84\%) of the $>20,000$ water samples had oil concentrations below $1 \mathrm{ppb}$ [7].

Nevertheless, there has been concern that the process of biodegradation might 
increase the toxicity of spilled oil by generating partially oxidized intermediates released to the sea [8] [9]. We show here that $3 \mathrm{ppm}$ dispersed oil is not acutely toxic to mysid shrimps, a particularly sensitive species routinely used for environmental toxicity testing [10] [11], and that no acute toxicity becomes apparent as biodegradation proceeds at those concentrations.

\section{Materials and Methods}

Seawater (30 psu) was collected in June 2016 from Sandy Hook, New Jersey in large Nalgene $e^{\varpi}$ carboys, and aerated in the laboratory overnight. Nitrate and phosphate levels were below detection limits with simple laboratory colorimetric tests, but are likely to have been near 7 and $0.5 \mu \mathrm{M}$, respectively [12]. The biodegradation experiments were initiated the next day (Day 0 ) in twelve $1 \mathrm{~L}$ glass bottles, almost filling them with seawater, and adding $3 \mu \mathrm{l}$ of lightly weathered Black Sea oil (initial API gravity 32.7) premixed with Corexit 9500 at a dispersant to oil ratio of 1:20. As seen in Figure 1, the evaporative weathering removed most compounds with fewer than 10 carbons, so the majority of benzene, toluene, ethylbenzene and the xylenes had been lost before the oil was dispersed. (Note that compounds with up to 15 carbons were lost during the extraction and concentration of the oil even in the $t=0$ samples (Figure 1 ) so they might have been lost by evaporation by day 8 . Nevertheless, in view of the substantial degradation of non-volatile hydrocarbons, we think that biodegradation is a more likely fate.) After transiently sealing with Teflon tape, all bottles were shaken to fully disperse the oil. The sealing tape was removed, the bottles completely filled

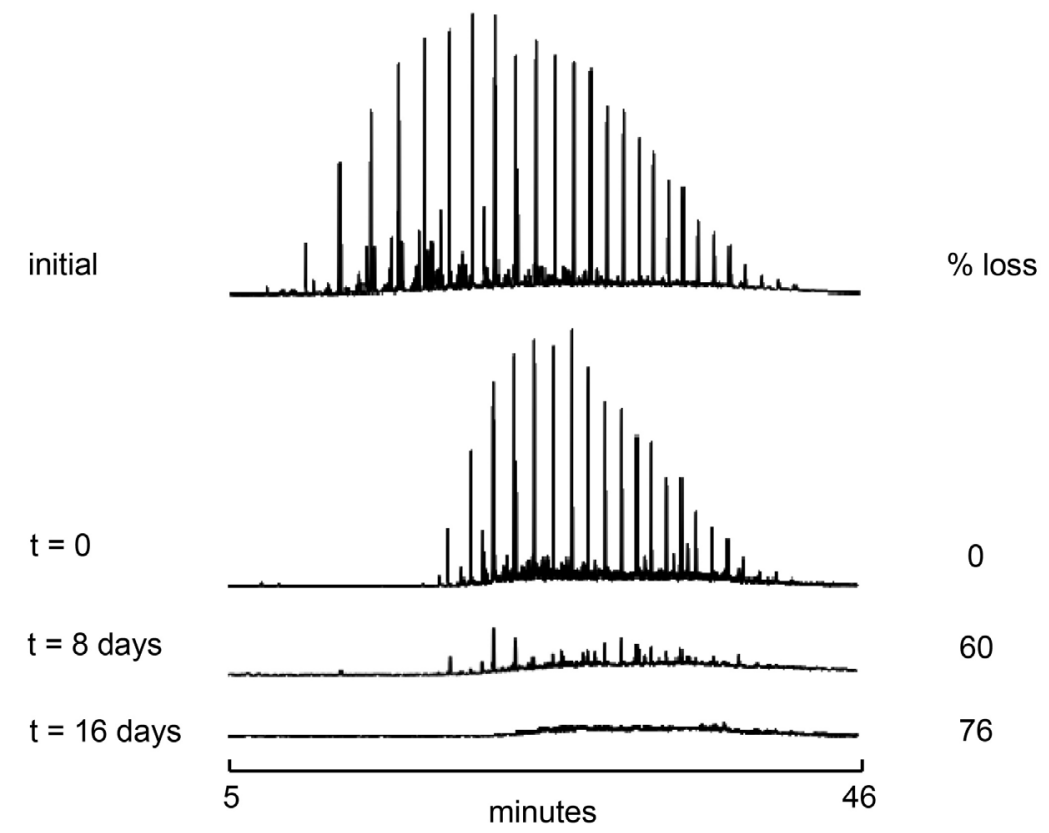

Figure 1. GC/MS total ion chromatograms of the lightly weathered oil used here, and oils extracted at various times from the experiment. \% loss is calculated from the extracted oil at $\mathrm{t}=0$, using hopane as a conserved internal marker, and the traces are normalized to hopane content. 
with seawater, a Teflon stir bar added, and the bottles stirred slowly (20 rpm) throughout the experiment. The incubations were carried out in an environmental chamber at the temperature $(26 \pm 1 \mathrm{C})$ and light conditions $(16: 8 \mathrm{~h}$ light:dark) mandated for the USEPA-defined test [13] [14]. We specifically used "whole oil" dosing rather than "water accommodated fractions" because the latter remove the possibility of physical oiling in formal toxicity tests. In reality both chemical toxicity and physical oiling are potential issues following an oil spill, and we include both here.

Mysid shrimp (Americamysis bahia) were purchased from Aquatic Research Organisms, (Hampton, NH 03843) so that all organisms were 5 - 7 days old when each test began. They were held in a $20 \mathrm{~L}$ holding tank of artificial seawater (30 psu) prepared from Instant Ocean Sea Salts and deionized water.

Biodegradation began as the bottles were assembled at Day 0. Duplicate mysid toxicity tests in general agreement with EPA-821-R-02-012 \& 014 [13] [14] were begun at day $0,4,8,12$ and 16 in the ongoing incubations. Ten randomly picked mysids were placed into replicate bottles on the appropriate day, fed approximately 150 brine shrimp nauplii per mysid, and observed for mortality or morbidity every $24 \mathrm{~h}$. After assessment at $96 \mathrm{~h}$, tests were terminated by the addition of dichloromethane, and the oil was extracted and analyzed by GC/MS to establish the extent of biodegradation [15] using hopane as a conserved internal marker [16]. Duplicate experimental bottles were also extracted immediately after initial assembly.

\section{Results}

\subsection{Oil Biodegradation}

Figure 1 shows GC/MS total ion chromatograms of the initial oil used in the experiment, and samples extracted from the incubations at various times. In order to mimic oil that had been at sea for less than a day and thus would be a likely target for aerial dispersant application, we used a partially weathered oil that had lost only the most volatile components-the first significant peak in the chromatogram is decane. Extraction of this oil from the experimental bottles with dichloromethane, and then concentrating the extract by evaporation, led to the loss of further material and the first prominent peak in the $t=0$ sample is pentadecane.

As expected [15] [17]-[26], biodegradation of oil under these conditions was rapid, and about half of the oil was biodegraded in the first four days. This rate is slightly faster than in most other measurements, most likely because the incubation temperature was somewhat warmer $\left(26^{\circ} \mathrm{C}\right)$ than the prevailing temperatures when the water was collected $\left(19^{\circ} \mathrm{C}\right)$. Essentially all the $n$-alkanes and most of the resolvable iso-alkanes, and parent two- and three-ring aromatics had been consumed within the first four days. But as shown schematically in Figure 2, more alkylated aromatics, such as $\mathrm{C}_{4}$-naphthalenes and phenanthrenes, and $\mathrm{C}_{2}$-chrysenes are degraded more slowly [15] [27], and their biodegradation was 


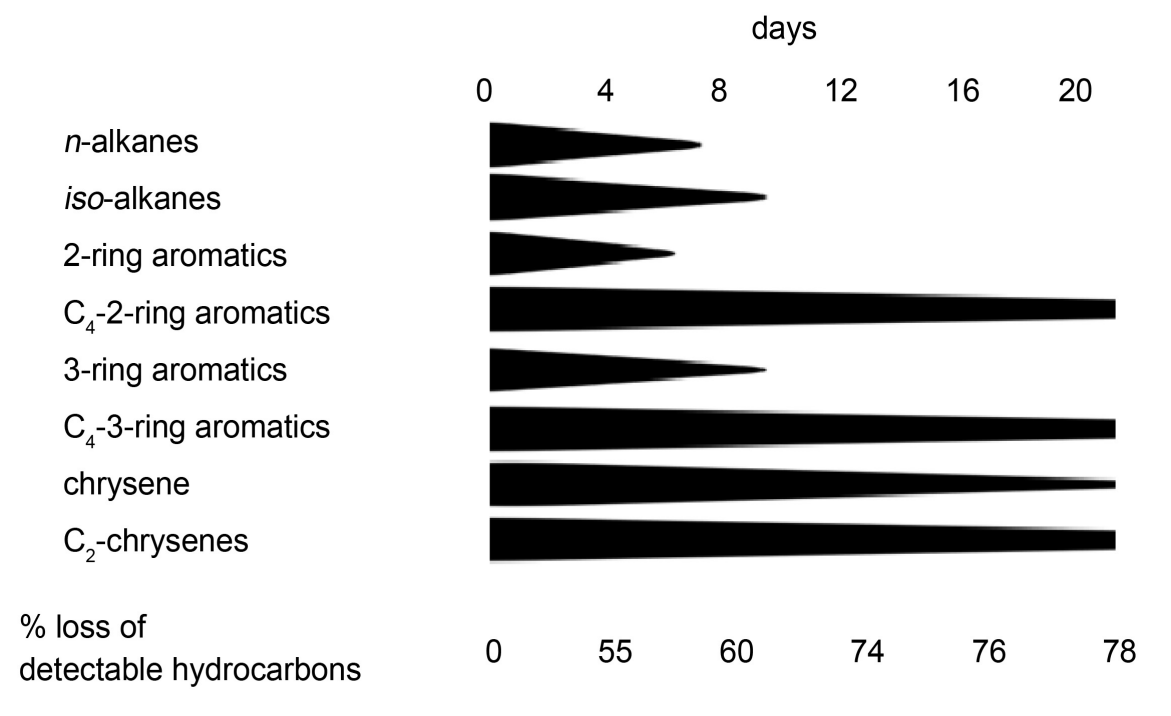

Figure 2. Schematic representation of when the biodegradation of different components was occurring, as monitored by the disappearance of the components relative to hopane as a conserved internal marker. $\mathrm{n}$-alkanes comprise $n \mathrm{C} 15-n \mathrm{C} 36$, iso-alkanes comprise norpristane, pristane and phytane, 2-ring aromatics comprise naphthalene and fluorene, and the $\mathrm{C}_{4}$ notation indicates those components with four methyl-equivalent additions. 3-ring aromatics comprise phenanthrene and dibenzothiophene. Approximately 20\% $50 \%$ of the initial $\mathrm{C}_{4}$-3-ring aromatics, chrysene and $\mathrm{C}_{2}$-chrysenes remained at the end of the experiment.

proceeding throughout the experiment.

By the end of the experiment, at 20 days, some $78 \%$ of the total detectable hydrocarbons had been consumed by the indigenous seawater microbiota, including $50 \%-80 \%$ of the initial $\mathrm{C}_{4}$-3-ring aromatics, chrysene and $\mathrm{C}_{2}$-chrysenes.

\subsection{Mysid Toxicity}

All mysids survived their $96 \mathrm{~h}$ incubations (Table 1), from those exposed to the freshest (albeit partially weathered) dispersion to those exposed when the biodegraded oil contained almost no resolvable components except the more alkylated aromatics. They appeared healthy and fully motile throughout.

\section{Discussion}

Untreated oil slicks may persist for some time, killing birds and mammals, and potentially stranding on shorelines. Dispersants were originally developed to protect birds and other charismatic wildlife from oiling by floating slicks [28], and it took some time for the remarkably rapid biodegradation of dispersed oil that follows successful dispersion to be appreciated [15]-[26] [29]. The toxicity of dispersed crude oil is relatively well understood [3] [4] [6] [30] [31], and dispersed oil soon dilutes to levels below acute concern [5]. But a nagging disquiet remained that perhaps the biodegradation process released intermediates that might be more toxic than the initial hydrocarbons in the spill. On the one hand, this is not an unreasonable concern, since the precise biodegradation pathways 
Table 1. Mysid survival in the 5 tests. Each test was performed in duplicate. There were no signs of any morbidity during the tests.

\begin{tabular}{cccccc}
\hline $\mathrm{hr}$ & Initiated day 0 & Initiated day 4 & Initiated day 8 & Initiated day 12 & Initiated day 16 \\
\hline 0 & $100 \%$ & $100 \%$ & $100 \%$ & $100 \%$ & $100 \%$ \\
24 & $100 \%$ & $100 \%$ & $100 \%$ & $100 \%$ & $100 \%$ \\
48 & $100 \%$ & $100 \%$ & $100 \%$ & $100 \%$ & $100 \%$ \\
72 & $100 \%$ & $100 \%$ & $100 \%$ & $100 \%$ & $100 \%$ \\
96 & $100 \%$ & $100 \%$ & $100 \%$ & $100 \%$ & $100 \%$ \\
\hline
\end{tabular}

of the myriad hydrocarbons in crude oils and refined products, often with substantial but uncharacterized alkylation, are unknown. Fourier transform ion cyclotron resonance mass spectrometry is characterizing a variety of partially oxidized hydrocarbons that may be metabolic, or possibly photochemically-generated, intermediates generated after oil release [32] [33]. But on the other hand, we know that all known aerobic hydrocarbon metabolism begins with oxidation requiring the reduction of one of the two atoms of diatomic oxygen to water at the expense of an $\mathrm{NADH}$ [27], so any organism that promiscuously oxidized hydrocarbons to dead-end metabolites would put itself at a potentially significant energetic disadvantage. In any case, we set out to test the potential toxicity of biodegrading oil under conditions that are as close to natural as possible. In fact, dispersed oil typically dilutes to much lower than $1 \mathrm{ppm}$ [7], but such concentrations cannot provide enough oil for the analysis of biodegradation in experimentally tractable volumes. We therefore did our experiments at $3 \mathrm{ppm}$ oil, which is higher than the vast majority of samples measured in the field [7]. We believe our demonstration of no acute toxicity to a sensitive species indicates that the biodegradation process, which is essentially complete in a few weeks following oil release, is very unlikely to cause acute toxicity at environmentally-relevant concentrations. Since oil hydrocarbons are biodegraded so promptly, chronic toxicity from dispersed oil also seems very unlikely [34].

\section{Conflicts of Interest}

The authors declare no conflicts of interest regarding the publication of this paper.

\section{References}

[1] Prince, R.C. (2015) Oil Spill Dispersants: Boon or Bane? Environmental Science \& Technology, 49, 6376-6384. https://doi.org/10.1021/acs.est.5b00961

[2] Lewis, A. and Prince, R.C. (2018) Integrating Dispersants in Oil Spill Response in Arctic and Other Icy Environments. Environmental Science \& Technology, 52, 6098-6112. https://doi.org/10.1021/acs.est.7b06463

[3] Singer, M.M., Aurand, D., Bragin, G.E., Clark, J.R., Coelho, G.M., Sowby, M.L. and Tjeerdema, R.S. (2000) Standardization of the Preparation and Quantitation of Water-Accommodated Fractions of Petroleum for Toxicity Testing. Marine Pollution 
Bulletin, 40, 1007-1016. https://doi.org/10.1016/S0025-326X(00)00045-X

[4] Barron, M.G., Hemmer, M.J. and Jackson, C.R. (2013) Development of Aquatic Toxicity Benchmarks for Oil Products Using Species Sensitivity Distributions. Integrated Environmental Assessment and Management, 9, 610-615. https://doi.org/10.1002/ieam.1420

[5] Lee, K., Nedwed, T., Prince, R.C. and Palandro, D. (2013) Lab Tests on the Biodegradation of Chemically Dispersed Oil Should Consider the Rapid Dilution that Occurs at Sea. Marine Pollution Bulletin, 73, 314-318. https://doi.org/10.1016/j.marpolbul.2013.06.005

[6] Bejarano, A.C., Clark, J.R. and Coelho, G.M. (2014) Issues and Challenges with Oil Toxicity Data and Implications for Their Use in Decision Making: A Quantitative Review. Environmental Toxicology and Chemistry, 33, 732-742. https://doi.org/10.1002/etc.2501

[7] Wade, T.L., Sericano, J.L., Sweet, S.T., Knap, A.H. and Guinasso Jr., N.L. (2016) Spatial and Temporal Distribution of Water Column Total Polycyclic Aromatic Hydrocarbons (PAH) and Total Petroleum Hydrocarbons (TPH) from the Deepwater Horizon (Macondo) Incident. Marine Pollution Bulletin, 103, 286-293. https://doi.org/10.1016/j.marpolbul.2015.12.002

[8] Middaugh, D.P., Chapman, P.J., Shelton, M.E., McKenney Jr., C.L. and Courtney, L.A. (2002) Effects of Fractions from Biodegraded Alaska North Slope Crude Oil on Embryonic Inland Silversides, Menidia beryllina. Archives of Environmental Contamination and Toxicology, 42, 236-243. https://doi.org/10.1007/s00244-001-0006-5

[9] Hansen, B.H., Farkas, J., Nordtug, T., Altin, D. and Brakstad, O.G. (2018) Does Microbial Biodegradation of Water-Soluble Components of Oil Reduce the Toxicity to Early Life Stages of Fish? Environmental Science \& Technology, 52, 4358-4366. https://doi.org/10.1021/acs.est.7b06408

[10] Nimmo, D.R. and Hamaker, T.L. (1982) Mysids in Toxicity Testing: A Review. In: Morgan, M.D., Ed., Ecology of Mysidacea. Developments in Hydrobiology, Springer, Dordrecht, 71-178. https://doi.org/10.1007/978-94-009-8012-9_18

[11] Barron, M.G., Conmy, R.N., Holder, E., Meyer, P., Wilson, G.J., Principe, V.E. and Willming, M.M. (2017) Overview of Aquatic Toxicity Testing under the US EPA Oil Research Program. International Oil Spill Conference Proceedings, 2017, 2017-063. https://doi.org/10.7901/2169-3358-2017.1.2017-063

[12] Louanchi, F. and Najjar, R.G. (2001) Annual Cycles of Nutrients and Oxygen in the Upper Layers of the North Atlantic Ocean. Deep Sea Research Part II: Topical Studies in Oceanography, 48, 2155-2171. https://doi.org/10.1016/S0967-0645(00)00185-5

[13] USEPA (2002) Methods for Measuring the Acute Toxicity of Effluents and Receiving Waters to Freshwater and Marine Organisms. Environmental Protection Agency, Cincinnati, $\mathrm{OH}$.

[14] USEPA (2002) Short-Term Methods for Estimating the Chronic Toxicity of Effluents and Receiving Waters to Freshwater and Marine and Estuarine Organisms. 3rd Edition, Environmental Protection Agency, Cincinnati, OH.

[15] Prince, R.C., McFarlin, K.M., Butler, J.D., Febbo, E.J., Wang, F.C. and Nedwed, T.J. (2013) The Primary Biodegradation of Dispersed Crude Oil in the Sea. Chemosphere, 90, 521-526. https://doi.org/10.1016/j.chemosphere.2012.08.020

[16] Prince, R.C., Elmendorf, D.L., Lute, J.R., Hsu, C.S., Haith, C.E., Senius, J.D., Dechert, G.J., Douglas, G.S. and Butler, E.L. (1994) 17.Alpha.(H)-21.Beta.(H)-Hopane as a Conserved Internal Marker for Estimating the Biodegradation of Crude Oil. 
Environmental Science \& Technology, 28, 142-145. https://doi.org/10.1021/es00050a019

[17] Prince, R.C. and Butler, J.D. (2014) A Protocol for Assessing the Effectiveness of Oil Spill Dispersants in Stimulating the Biodegradation of Oil. Environmental Science and Pollution Research, 21, 9506-9510. https://doi.org/10.1007/s11356-013-2053-7

[18] McFarlin, K.M., Prince, R.C., Perkins, R. and Leigh, M.B. (2014) Biodegradation of Dispersed Oil in Arctic Seawater at-1 C. PLoS ONE, 9, e84297. https://doi.org/10.1371/journal.pone.0084297

[19] Brakstad, O.G., Nordtug, T. and Throne-Holst, M. (2015) Biodegradation of Dispersed Macondo Oil in Seawater at Low Temperature and Different Oil Droplet Sizes. Marine Pollution Bulletin, 93, 144-152.

[20] Prince, R.C., Nash, G.W. and Hill, S.J. (2016) The Biodegradation of Crude Oil in the Deep Ocean. Marine Pollution Bulletin, 111, 354-357.

[21] Wang, J., Sandoval, K., Ding, Y., Stoeckel, D., Minard-Smith, A., Andersen, G., Dubinsky, E.A., Atlas, R. and Gardinali, P. (2016) Biodegradation of Dispersed Macondo Crude Oil by Indigenous Gulf of Mexico Microbial Communities. Science of the Total Environment, 557, 453-468. https://doi.org/10.1016/j.scitotenv.2016.03.015

[22] Garneau, M.Ė., Michel, C., Meisterhans, G., Fortin, N., King, T.L., Greer, C.W. and Lee, K. (2016) Hydrocarbon Biodegradation by Arctic Sea-Ice and Sub-Ice Microbial Communities during Microcosm Experiments, Northwest Passage (Nunavut, Canada). FEMS Microbiology Ecology, 92, fiw130.

https://doi.org/10.1093/femsec/fiw130

[23] Prince, R.C., Kelley, B.A. and Butler, J.D. (2016) Three Widely-Available Dispersants Substantially Increase the Biodegradation of Otherwise Undispersed Oil. Journal of Marine Science: Research \& Development, 6, 2. https://doi.org/10.4172/2155-9910.1000183

[24] Prince, R.C., Butler, J.D. and Redman, A.D. (2017) The Rate of Crude Oil Biodegradation in the Sea. Environmental Science \& Technology, 51, 1278-1284. https://doi.org/10.1021/acs.est.6b03207

[25] Brakstad, O.G., Ribicic, D., Winkler, A. and Netzer, R. (2018) Biodegradation of Dispersed Oil in Seawater Is Not Inhibited by a Commercial Oil Spill Dispersant. Marine Pollution Bulletin, 129, 555-561. https://doi.org/10.1016/j.marpolbul.2017.10.030

[26] Ribicic, D., McFarlin, K.M., Netzer, R., Brakstad, O.G., Winkler, A., Throne-Holst, M. and Størseth, T.R. (2018) Oil Type and Temperature Dependent Biodegradation Dynamics-Combining Chemical and Microbial Community Data through Multivariate Analysis. BMC Microbiology, 18, 83.

https://doi.org/10.1186/s12866-018-1221-9

[27] Prince, R.C. and Walters, C.C. (2016) Biodegradation of Oil Hydrocarbons and Its Implications for Source Identification. In: Stout, S.A. and Wang, Z., Eds., Standard Handbook Oil Spill Environmental Forensics, 2nd Edition, Elsevier, ¡Amsterdam, 869-916. https://doi.org/10.1016/B978-0-12-803832-1.00019-2

[28] National Research Council (2005) Oil Spill Dispersants: Efficacy and Effects. National Academy Press, Washington DC.

[29] Hazen, T.C., Dubinsky, E.A., DeSantis, T.Z., Andersen, G.L., Piceno, Y.M., Singh, N., Jansson, J.K., Probst, A., Borglin, S.E., Fortney, J.L., Stringfellow, W.T., Bill, M., Conrad, M.S., Tom, L.M., Chavarria, K.L., Alusi, T.R., Lamendella, R., Joyner, D.C., Spier, C., Baelum, J., et al. (2010) Deep Sea Oil Plume Enriches Indigenous 
Oil-Degrading Bacteria. Science, 330, 204-208.

https://doi.org/10.1126/science.1195979

[30] Redman, A.D., Parkerton, T.F., McGrath, J.A. and Di Toro, D.M. (2012) PETROTOX: An Aquatic Toxicity Model for Petroleum Substances. Environmental Toxicology and Chemistry, 31, 2498-506. https://doi.org/10.1002/etc.1982

[31] Adams, J., Sweezey, M. and Hodson, P.V. (2014) Oil and Oil Dispersant Do Not Cause Synergistic Toxicity to Fish Embryos. Environmental Toxicology and Chemistry, 33, 107-114. https://doi.org/10.1002/etc.2397

[32] Ruddy, B.M., Huettel, M., Kostka, J.E., Lobodin, V.V., Bythell, B.J., McKenna, A.M., Aeppli, C., et al. (2014) Targeted Petroleomics: Analytical Investigation of Macondo Well Oil Oxidation Products from Pensacola Beach. Energy Fuels, 28, 4043-4050. https://doi.org/10.1021/ef500427n

[33] Chen, H., Hou, A., Corilo, Y.E., Lin, Q., Lu, J., Mendelssohn, I.A., Zhang, R., Rodgers, R.P. and McKenna, A.M. (2016) 4 Years after the Deepwater Horizon Spill: Molecular Transformation of Macondo Well Oil in Louisiana Salt Marsh Sediments Revealed by FT-ICR Mass Spectrometry. Environmental Science \& Technology, 50, 9061-9069. https://doi.org/10.1021/acs.est.6b01156

[34] Langdon, C.J., Stefansson, E.S., Pargee, S.M., Blunt, S.M., Gage, S.J. and Stubblefield, W.A. (2016) Chronic Effects of Non-Weathered and Weathered Crude Oil and Dispersant Associated with the Deepwater Horizon Incident on Development of Larvae of the Eastern Oyster, Crassostrea virginica. Environmental Toxicology and Chemistry, 35, 2029-2040. https://doi.org/10.1002/etc.3352 